\title{
A PUBLICIDADE ENGANOSA E ABUSIVA E A TUTELA DO CONSUMIDOR
}

Bruna Nayara dos Santos Silva

Aluna do Curso de Direito da FA7.

Artigo sob orientação da prof ${ }^{\mathrm{a}}$. Ms. Ângela Teresa Gondim Carneiro (FA7)

advogada.brunasantos@gmail.com

Sumário: Introdução. 1. A publicidade. 2. A evolução da publicidade no mercado de consumo. 3. Princípios da publicidade. 4. Técnicas publicitárias. 5. A publicidade ilícita. Considerações finais.

Resumo: O presente artigo se propõe a fazer uma análise sobre a sociedade dita pós-moderna, quanto à construção de seus padrões culturais e a forma como eles estão intimamente ligados ao uso da publicidade ilícita. $\mathrm{O}$ controle dessas práticas perniciosas à formação do comportamento dos consumidores deve se dar em dois âmbitos distintos, mas complementares, a saber, o jurídico e o privado, cabendo ao CONAR, como órgão de controle exclusivamente privado, exercer o controle ético sobre os profissionais de publicidade e propaganda, de forma a cumprir com o mandamento constitucional de defesa do consumidor.

Palavras-chave: Publicidade. Publicidade enganosa e abusiva. Consumidor. Autorregulamentação.

\section{INTRODUÇÃo}

O presente artigo tem como objetivo cercear os limites da atuação publicitária em relação à prática da publicidade enganosa e abusiva, voltando-se, com esse fim, para a perspectiva da autorregulamentação no controle dessas práticas ilícitas, tendo em vista a proteção e defesa do consumidor.

A sociedade contemporânea tem se confrontando diariamente com diversos tipos de apelos publicitários. Os meios de comunicação de massa aparecem como instrumentos que visam influenciar o consumidor, condicionando-o a certo comportamento. Muitas dessas condutas são irregulares e se dirigem, sobretudo, às grandes populações, daí salientarmos a existência de um alto grau de lesividade, abusando da boa-fé dos consumidores e acarretando-lhes prejuízos de diversas ordens.

Diante desse cenário, torna-se imperativo ressaltarmos a importância do controle dessa atividade. O presente artigo se propõe, então, a examinar como a autorregulamentação cumpre o seu papel diante dos seus partícipes (anunciantes, fornecedores, empresas, consumidores) e se esta desenvolve seu compromisso, em direção à proteção do consumidor. A intenção não é esgotar o assunto, mas apenas analisá-lo de forma sucinta. 


\section{A Publicidade}

Para seguirmos em nossa análise quanto à publicidade e suas implicações sociais e jurídicas, ultrapassaremos, inicialmente, algumas questões que formam o arcabouço dessa discussão. Compreendemos que se faz necessário entender o contexto socioeconômico da sociedade em que estamos inseridos, buscando as características que lhe são intrínsecas e que a torna vulnerável às condutas ilícitas da comunicação de massa.

A principal característica da sociedade pós-moderna consiste na alta propensão ao consumo, por isso a denominação de sociedade de consumo. Sua delineação se iniciou com o advento da Revolução Industrial e intensificou-se após a Segunda Guerra Mundial. No entanto, as mudanças sociais não ficaram limitadas ao século XIX. Nos últimos anos, o Brasil assiste a profundas mudanças no cenário econômico com o crescimento do mercado de consumo, devido, principalmente, à estabilidade econômica resultante da diminuição da inflação e do aumento do poder aquisitivo das classes sociais menos favorecidas.

Jamerson (2007) descreve o movimento histórico contemporâneo como um determinante cultural, caracterizado principalmente pelo esmaecimento dos laços sociais ditados pelo estilo de vida pós-moderno baseado no consumismo exacerbado:

\footnotetext{
O que ocorre é que a produção estética hoje está integrada à produção das mercadorias em geral: a urgência desvairada da economia em produzir novas séries de produtos que cada vez mais pareçam novidades (de roupas a aviões), com um ritmo de turn over cada vez maior, atribui uma posição e uma função estrutural cada vez mais essenciais à inovação estética e ao experimentalismo. (2007, p. 30).
}

Jamerson (2007) afirma que o ponto central do pós-modernismo consiste na mercantilização, que reduz a produção cultural e artística a outdoors e embalagens de produtos famosos, o que resulta na ausência de profundidade e na superficialidade dos homens, levando-os ao total enfraquecimento da identidade social na cultura como um todo, seja na arquitetura, nas artes, na música ou no cinema.

Houve, na verdade, uma transformação dos objetos em mercadoria e um esmaecimento dos laços sociais e afetivos, que é uma espécie de precondição indispensável para o consumismo, possibilitando ao homem criar para si uma espécie de mundo-objeto, cercado por paredes, permitindo-lhe estar alheio às questões sociais, como o uso do trabalho infantil na produção dos seus objetos de desejo consumerista, fenômeno chamado pelo autor de esquizofrenia da consciência coletiva. (JAMERSON, 2007).

Nessa sociedade consumista, o indivíduo desaparece frente à ideia da generalização, consistente na divisão da população em diversos grupos, incomunicáveis entre si e por isso enfraquecidos, fenômeno chamado de pluralismo social e que está baseado no relativismo identitário e na eliminação da objetividade na investigação social. Daí a sua vinculação com o consumo generalizado, devido à busca de satisfação das necessidades inventadas pela mídia que levam à padronização dos grupos e não da sociedade como um todo.

O pós-modernismo é alocado numa espécie de "capitalismo tardio", em que os ideais revolucionários burgueses - liberdade e igualdade - perderam-se na utopia e nunca chegaram à realização social. A partir daí, surge a proposição infundada e tendenciosa de que "o mercado está na natureza humana", como se houvesse desaparecido a capacidade humana de crítica e transformação, diante do poderio devastador do consumismo midiático. (JAMERSON, 2007).

Esta sociedade do consumo se caracteriza pela cultura do capitalismo, onde forma, conteúdo, estética e aparência são ditadas por valores criados pelo mercado: sobre o que se deve usar, comprar e como se satisfazer. E isso numa lógica descartável e efêmera, afinal, os novos 
produtos já nascem para ser substituídos num curto espaço de tempo. A referência absoluta dessa sociedade é a busca desenfreada pela felicidade que nesse contexto se torna mensurável e dotada de uma ideologia mercadológica, baseada no binômio: necessidade x satisfação. (BAUDRILLARD, 2007).

Outra fundamental característica e instrumento de dominação dessa sociedade do consumo pós-moderna consiste na comunicação de massa, que ocorre através de diversos instrumentos, todos bastante eficazes, em que "toda a informação política, histórica e cultural é acolhida da mesma forma, simultaneamente anódina e miraculosa, do $<<$ faits $\left.\operatorname{divers}^{1}\right\rangle>$, em que o conteúdo das mensagens, [...], em grande parte são indiferentes. $\mathrm{O}$ nosso empenhamento não nos acompanha e os meios de comunicação não nos orientam para o mundo, oferecem-nos para o consumo [...]". (BAUDRILLARD, 2007, p. 24-25).

Para Efing (2012), essa nova arquitetura social deve-se à massificação da produção, do consumo e do crédito, na qual, para que sejam alcançados altos índices de vendas, é preciso uma ampla disseminação da publicidade e das estratégias mercadológicas, que tornam o consumidor vulnerável às ações dos produtores e fornecedores de bens e serviços.

O meio utilizado pela publicidade é, basicamente, a comunicação. Esta, de forma genérica, baseia-se em um processo humano e social fundamental para a vida em sociedade. Abrange tanto a comunicação interpessoal como a comunicação de massa e faz uso da palavra falada, da escrita, dos símbolos, do gesto, dos sons, da imagem, da radiodifusão, do cinema. Seu espectro é muito amplo.

Antes de prosseguir na explanação dos temas propostos é preciso definir os conceitos de propaganda e publicidade, vocábulos que não são sinônimos, embora muitas vezes sejam usados como tal, de forma que o termo publicidade significa divulgar, tornar público, enquanto a palavra propaganda corresponde à ideia de implantar, de incutir uma ideia, uma crença na mente de outrem. Entretanto, o Superior Tribunal de Justiça (STJ) não aplica tal diferenciação, utilizando os dois termos indistintamente. (SANT'ANNA, 2002).

Sampaio (2003) ensina que a publicidade é uma das grandes formadoras do ambiente cultural e social de nossa época, atuando sobre os centros sensoriais, emocionais e lógicos do consumidor. Ela trabalha modelando e combinando dados culturais existentes e novos sobre os instintos mais fortes dos seres humanos, como o medo, a competitividade, a inveja, o fascínio pelo novo, a insegurança e a necessidade de autorrealização.

Pode-se, então, concluir com as palavras de Xavier (2012, p. 119):

A atuação publicitária funciona como um efetivo instrumento de comunicação entre
os agentes econômicos e os consumidores. Esta comunicação, entretanto, não ocorre
na forma de monólogo, mas sim de um diálogo perfeito, sendo que cada mensagem
publicitária recebe uma resposta própria, advinda do mercado consumerista, que
muitas vezes, de forma ingênua, trava essa conversação sem ter conhecimento de toda
a complexidade que a situação envolve.

Daí o entendimento de que "a publicidade é uma técnica de comunicação de massa, paga com a finalidade precípua de fornecer informações, desenvolver atitudes e provocar ações benéficas para os anunciantes, geralmente para vender produtos e serviços". (SANT'ANNA, 2002, p. 76).

\footnotetext{
${ }^{1}$ Faits divers (pronuncia-se fé-divér; em francês, literalmente, "fatos diversos”) é uma expressão de jargão jornalístico. São fatos desconectados de historicidade jornalística, ou seja, referem-se apenas ao seu carácter interno e seu interesse como fato inusitado, pitoresco. Em geral, remetem a temas considerados "leves", curiosos, não muito sérios e sem comprometer seriamente ninguém.
} 


\section{A Evolução do Controle da Publicidade no Mercado de Consumo}

O Direito do Consumidor é um ramo transversal entre o direito público e o privado. O sujeito de direitos desse novo direito, que se pode chamar de tutelar ou protetório, antes da Carta Magna de 1988, era identificado com outros nomes, como "contratante", "cliente", "comprador", denominações que vislumbravam apenas o indivíduo detentor de direitos, ocupante de uma posição momentânea relacional específica, visão que não permitia que se enxergasse a sua posição na sociedade como membro de um grupo com interesses semelhantes, os chamados interesses individuais homogêneos, coletivos e difusos. (MARQUES, 2012).

O Direito do Consumidor teve sua reflexão jurídica inicial lançada nos Estados Unidos, no discurso do então presidente John F. Kennedy, em 1962, em que se concluiu que "todos somos consumidores" e, consequentemente, detentores de direitos, um novo desafio para o mercado. A própria ONU (Organização das Nações Unidas), em 1985, estabeleceu as diretrizes para a legislação e a consolidação da ideia de um direito social e econômico, um direito de igualdade material do mais fraco, dos vulneráveis, frente à superioridade dos fornecedores. (MARQUES, 2012).

Marques (2012, p. 30), comentando o surgimento legislativo do direito do consumidor, que somente ocorreu no Brasil após o seu desenvolvimento nos Estados Unidos e países europeus, declara que:

[...] o direito do consumidor é direito social típico das sociedades capitalistas industrializadas, onde os riscos do progresso devem ser compensados por uma legislação tutelar (protetiva) e subjetivamente especial (para aquele sujeito ou grupo de sujeitos).

Esse novo ramo do direito recebeu tratamento especial pela Constituição Federal do Brasil, tendo sido elevado à categoria de direito fundamental. Passando a compor os chamados direitos de segunda geração, em que se exige do Estado uma posição proativa, de atuação positiva para defesa de toda a sociedade. (NUNES JUNIOR, 2010).

Por esse motivo, a Carta Magna de 1988, ao tratar dos Direitos e Garantias Fundamentais, estabelece, em seu artigo $5^{\circ}$, XXXII, que "o Estado promoverá, na forma da lei, a defesa do consumidor". Segundo Garcia (2010, p. 3), "a inclusão da defesa do consumidor como direito fundamental na Constituição Federal vincula o Estado e todos os demais operadores a aplicar e efetivar a defesa deste ente vulnerável, considerado mais fraco na sociedade".

A disciplina infraconstitucional da proteção e defesa do consumidor foi elevada a princípio da ordem econômica, consistindo em um microssistema próprio, justo e coerente. Seus princípios e normas devem prevalecer sobre os demais, excetuando-se apenas a própria Constituição Federal. Dessa nova condição advêm várias consequências, principalmente no campo prático, onde a tutela do consumidor passa a ocupar posição de preeminência nos horizontes jurídicos. (NUNES, 2011).

A proteção ao consumidor inicia-se antes mesmo da realização do contrato de consumo, uma vez que a relação de consumo começa quando ainda existe apenas uma expectativa de consumo gerada pelo uso de técnicas de estimulação do consumo, dentre as quais a principal é a publicidade. Ao legislador coube a escolha por tutelar esse fenômeno que gera impacto incalculável na vida do consumidor. (BENJAMIN et al., 2012).

O Código de Defesa do Consumidor (CDC) não trata de regular especificamente a publicidade, mas somente coibir suas formas ilícitas, a saber, a publicidade enganosa e abusiva. Efing (2012, p. 96) destaca que: "até a edição do CDC, apenas existiam regras éticas sobre o exercício da publicidade, nenhuma das quais oferecia proteção ao consumidor propriamente".

No que tange ao objeto do controle, bem declararam Benjamin et al. (2007, p. 312): "O controle não é exercido de maneira isolada sobre a atividade publicitária. Insere-se em um contexto mais amplo de disciplina da atividade produtiva e comercial". 
A regulamentação, no Direito brasileiro, resulta da composição de dois sistemas originários: o primeiro é o que se chama de exclusivamente estatal, em que somente o Estado possui legitimidade para intervir na atividade publicitária; o outro é o exclusivamente privado, em que, em oposição ao anterior, somente atuam os entes privados.

Da composição desses dois sistemas resulta a convivência de forma complementar, tanto das leis estatais, da Constituição Federal e do CDC, como das normas criadas pelos próprios partícipes publicitários, como o Código Brasileiro de Autorregulamentação Publicitária (CBAP), formando um sistema misto de proteção.

O CONAR possui função complementar ao sistema normativo estatal, ficando comprometido com os valores éticos. Sua atuação se dá basicamente na fiscalização da publicidade realizada no mercado, com a possibilidade de aplicação de sanções administrativas. Pode-se, então, concluir que "os limites éticos da atividade publicitária estão no respeito ao consumidor". (EFING, 2012, p. 105).

Fadel (2004, p.155) ensina:

O CONAR apresenta como finalidade maior zelar pela aplicação do Código Brasileiro de Autorregulamentação Publicitária, recebendo denúncias de consumidores, de autoridades, de associados ou mesmo de sua diretoria, em face de qualquer empresa do mercado publicitário. Se não houver conciliação e a denúncia for julgada procedente, o CONAR aplica sanção administrativa que, embora sem coerção legal, apresenta fortíssima coerção ética.

Seu surgimento deveu-se em parte ao sentimento de desconfiança que permeava o consumidor em relação à atividade publicitária e da ameaça do governo federal de sancionar uma lei que criava uma espécie de censura prévia a ser exercida por um departamento próprio de controle, o que significaria um retrocesso absurdo em matéria de liberdade de expressão.

Segundo Xavier (2012, p. 133): "na seara normativa, o CDC se encarrega de fornecer o arcabouço legal, regulando a atuação da publicidade [...]".

Por outro lado, ao CONAR cabe a tarefa de zelar pela aplicação do CBAP. No entanto, essas regras de autorregulamentação não compõem um corpo de normas jurídicas, não possuindo, por isso, generalidade, de forma que obrigam apenas os seus aderentes, operando apenas no plano normativo interno. (GRINOVER et al., 2007).

O artigo 16 do CBPA estabelece que as regras de autodisciplina da atividade publicitária também têm a função de servir como referência e fonte subsidiária pelo Poder Judiciário no exame de causas envolvendo questões publicitárias.

Coelho (2012, p. 379) observa que: “a autorregulamentação publicitária é, no Brasil, a mais interessante experiência de disciplina de atividade econômica por iniciativa dos próprios agentes nela envolvidos".

Os princípios que regem os processos instaurados no CONAR são: princípios do contraditório, da ampla defesa, da celeridade, da simplicidade e da proibição da censura prévia. Está ainda prevista a possibilidade de pedido liminar e de instâncias recursais. (FADEL, 2004). sobre a publicidade:

$\mathrm{Na}$ abordagem do tema, Grinover et al. (2007, p. 316) defende o controle exercido

De uma preocupação eminentemente individualista com a publicidade, priorizando mais o ato que a atividade, o legislador, modernamente, vem passando a exercer um controle social difuso do fenômeno. Ou seja, a publicidade [...] passa a ser vista como manifestação social difusa, daí concluindo-se que os malefícios que ocasionalmente provoca no mercado são, pela mesma razão, difusos. É em razão dessa nova perspectiva que se torna admissível a postulação - e deferimento - de pleitos indenizatórios difusos para o atuar publicitário patológico (em particular a publicidade enganosa e abusiva) [...].

RJurFA7, Fortaleza, v. X, n. 1, p. 79-90, abr. 2013 
O CDC inclui no rol de princípios a observância da boa-fé, que é uma regra de conduta para ambas as partes que devem agir pautadas pela honestidade e lealdade, e a garantia de proteção contra a publicidade enganosa e abusiva. Quando verificados atentados contra esses direitos básicos, a legislação brasileira permite a adoção de medidas sancionatórias, que possuem duplo objetivo, punir o infrator e reprimir o uso do mesmo tipo metodológico por outros agentes publicitários. (EFING, 2012).

Conforme ensinamento de Grinover et al. (2007), o CDC não veda a publicidade, mas apenas se posiciona contra as suas formas perniciosas ao consumidor, sendo essa proibição ampla e flexível para a publicidade enganosa e abusiva.

Diante desse cenário, é curial investigar se a autorregulamentação cumpre o seu papel diante de seus partícipes (anunciantes, fornecedores, empresas, consumidores) e se está cumprindo verdadeiramente com o compromisso da proteção do consumidor.

\section{Princípios da Publicidade} eles, destacam-se:

O CDC elenca uma gama de princípios orientadores da prática publicitária. Entre

\subsection{Princípio da veracidade da publicidade}

Benjamin leciona que esse é um princípio consagrado pela definição e proibição da publicidade enganosa, constante no artigo 37, § $1^{\circ}$, do CDC, sendo um dos mais importantes princípios da publicidade, nas palavras de Almeida (apud BENJAMIN, 2007, p. 328): “e também aquele que tem uma expressão legal mais antiga, mesmo quando o tratamento jurídico a publicidade não ultrapassa os limites da defesa da concorrência leal".

Conforme ensinamentos do professor Durandim (1997), um dos principais meios usados pela publicidade é a informação e a falsificação desta para alcançar seus objetivos, que consistem na obtenção de uma determinada conduta pelo consumidor. O citado autor afirma ainda que: "para induzir alguém ao erro, e modificar assim sua conduta, não é necessário lhe dar uma representação completamente falsa da situação; basta enganá-lo a respeito de um número limitado de pontos". (1997, p. 22). Esse obtuso uso da mentira ocorre porque o papel principal da publicidade não é informar ao consumidor sobre a existência do produto, mas influenciá-lo a consumir.

\section{Baudrillard (1995, p. 155) discorre que:}

O problema da veracidade da publicidade deve pôr-se da seguinte maneira: se os publicitários mentissem verdadeiramente, seria fácil desmascará-los - só que não o fazem, não por serem demasiado inteligentes, mas sobretudo porque a arte publicitária consiste principalmente na invenção de enunciados persuasivos, que não sejam nem verdadeiros nem falsos.

O próprio CBPA traz a honestidade e a verdade, em seus artigos 23 e 27, caput, como regras basilares do anúncio publicitário, como se vê, respectivamente, que "os anúncios devem ser realizados de forma a não abusar da confiança do consumidor, não explorar sua falta de experiência ou de conhecimento e não se beneficiar de sua credulidade" e "o anúncio deve conter uma apresentação verdadeira do produto oferecido, $[\ldots]$ ”.

Dessa forma, o anúncio publicitário não pode faltar com a verdade naquilo que anuncia, seja por afirmações ou omissões, estando vedada ainda a manipulação de frases, sons e imagens, com a finalidade de iludir o consumidor através da confusão e ambiguidade em suas declarações. (NUNES, 2011).

Lopes (2003, p. 30-31), em crítica à atividade publicitária, leciona que: 
[...] com relação exclusiva à Ética na Propaganda e Publicidade, nada se contempla em termos de bibliografia, por mais simplória que se pretenda. Há enorme escassez de informações. Há uma lacuna imensa, como se a Ética, a Lei, o Direito não importassem à atividade publicitária.

Com efeito, é inegável que a atividade publicitária é realizada muitas vezes à margem do direito e, por consequência, em desrespeito ao consumidor. Lida-se com uma bibliografia curta sobre o tema. As próprias pesquisas na área de publicidade demonstram que seus profissionais são muitas vezes relapsos em relação a esse assunto que, como se viu, possui vital importância para a sociedade como um todo, mas principalmente para o público infantojuvenil.

\title{
3.2 Princípio da transparência da fundamentação
}

Estipula ainda o artigo 36, parágrafo único, do CDC, que: "o fornecedor, na publicidade de seus produtos ou serviços, manterá, em seu poder, para informação dos legítimos interessados, os dados fáticos, técnicos e científicos que dão sustentação à mensagem”.

Segundo Benjamin et al. (2007, p. 334): "O fornecedor tem ampla liberdade para anunciar seus produtos ou serviços. Deve, contudo, fazê-lo sempre com base em elementos fáticos e científicos: é sua fundamentação".

Nunes (2011) traz a ideia de licença publicitária, que corresponde à liberalidade para compor um universo lúdico na apresentação do produto. No entanto, a ficção publicitária está limitada ao próprio produto ou serviço, que devem ser "reais" quanto às suas características, utilidades, preço, formas de pagamento, etc., sob pena de responsabilização do fornecedor.

Por último, deve-se ressaltar que o descumprimento de tal princípio gerará, além da repercussão cível e administrativa, tipificação penal, conforme o artigo 69, do CDC: "Deixar de organizar dados fáticos, técnicos e científicos que dão base à publicidade: Pena - Detenção de um a seis meses ou multa". Ocorre que, nesse caso, exige-se que haja o elemento subjetivo dolo, mas, no âmbito civil, a responsabilidade é objetiva, ou seja, prescinde de culpa.

Em resumo, Garcia (2010, p. 49) leciona que:

\begin{abstract}
Segundo o princípio da transparência, a relação contratual deve se mostrar clara para as partes, significando descrição e informação correta sobre o produto ou serviço a ser prestado. Este princípio se mostra de imensa importância, principalmente na fase pré-contratual, na qual o fornecedor usa de todos os meios para estimular o consumidor a aderir aos serviços e produtos oferecidos.
\end{abstract}

O que se busca com este princípio são a veracidade e a correção da publicidade, de forma a resultar num consumo consciente, livre de enganos, sendo resguardado o princípio da boa-fé objetiva. (GARCIA, 2010).

Outra questão importante é a proteção dos segredos industriais quanto à divulgação ampla, uma vez que a finalidade do Código é que sejam disponibilizadas informações relevantes ao consumidor, referentes à saúde e segurança, para que possa haver o adequado uso do produto e não informações sigilosas que não estão passíveis de ampla divulgação, como é o caso dos segredos industriais.

\subsection{Princípio da identificação obrigatória da publicidade}

O CDC, em seu artigo 36, caput, dispõe claramente que: "A publicidade deve ser veiculada de tal forma que o consumidor, fácil e imediatamente, a identifique como tal". Ainda sobre o tema, o item no 20 do Código de Ética dos Profissionais da Propaganda determina que "[...] A mistificação e o engodo que, escondendo a propaganda, decepcionam e confundem o público são expressamente repudiados pelos profissionais de propaganda". Dispõe ainda o CBAP, 
em seu artigo $9^{\circ}$, caput: "A atividade publicitária de que trata este Código será sempre ostensiva." e em seu $\S 1^{\text {o: }}$ "A alusão à marca de produto ou serviço, razão social do anunciante ou emprego de elementos reconhecidamente a ele associados atende ao princípio da ostensividade”.

Este princípio, que é reflexo do princípio da transparência, tem como principal consequência a criação para o fornecedor do dever de esclarecer ao consumidor todos os elementos do produto ou serviço, bem como todos os termos do contrato, sob pena de responsabilidade pela falha na informação. (GARCIA, 2010).

Dessa forma, a publicidade em respeito ao princípio em epígrafe, quando veiculada, deve ser ostensiva para possibilitar a sua completa identificação, de modo fácil e imediato pelo consumidor, sem qualquer esforço ou capacitação técnica, tanto do fornecedor (patrocinador), como também o produto ou o serviço oferecido.

Dessa forma, estão proibidas a publicidade clandestina e a subliminar, práticas dissimuladas de publicidade que ferem o ditame legal previsto no artigo $6^{\circ}$, III, do CDC, segundo o qual a informação adequada e clara é um direito básico do consumidor, em que a publicidade subliminar objetiva atingir apenas o inconsciente do consumidor, para que ele não perceba que está sendo influenciado. E a publicidade clandestina, ou invisível, é feita de forma sorrateira, escondida, não permitindo sua identificação como publicidade e, consequentemente, não deixando o consumidor construir suas defesas mentais quanto à influência midiática, sendo conhecida apenas pelos agentes envolvidos na sua promoção.

Para Benjamin et al.: "Publicidade que não quer assumir a sua qualidade é atividade que, de uma forma ou de outra, tenta enganar o consumidor. E o engano, mesmo que inocente, é repudiado pelo CDC". (2007, p. 331).

\section{As Principais Técnicas Publicitárias}

"A publicidade provocando as emoções nos indivíduos cuida de impulsionar seus desejos latentes com tanta força, que eles se sentem impelidos a trabalhar para poder satisfazê-los". (SANT'ANNA, 2002, p. 85).

A atuação publicitária só consegue lograr êxito na empreitada de mobilizar, persuadir e orientar um determinado público quando consegue identificar os seus sentimentos, a razão de seus atos, os seus pensamentos, desejos, necessidades, etc.

Como se pode perceber, todas essas características são internas ao indivíduo, por essa razão o uso das técnicas publicitárias só se dá após minuciosos estudos sobre o público-alvo, visando a melhor forma de persuadi-lo.

\subsection{O Puffing}

É a técnica publicitária da utilização do exagero. Sua principal característica é o uso de adjetivações exageradas, tais como "melhor carro do mundo" ou "a comida mais saborosa do mercado", com a finalidade de fixar a marca de forma impactante.

Sua utilização é limitada pela capacidade de tornar enganoso o anúncio, levando o consumidor a erro, incidindo sobre esta técnica o princípio da transparência da fundamentação. No entanto, essa técnica não será considerada ilícita enquanto apresentada como publicidade espalhafatosa, e com exacerbado exagero, de forma que qualquer pessoa, usando como parâmetro o homem médio, tenha capacidade de reconhecê-la como tal.

Serão utilizados dois parâmetros para a aferição de enganosidade, que são: o critério subjetivo, que necessita de uma avaliação crítica e pessoal do consumidor. Nesse aspecto, o elemento pessoal irá prevalecer em muitos casos, uma vez que leva em conta os gostos e 
motivações pessoais para respostas a chamadas publicitárias como "o melhor sabor", "o filme do ano" etc.; enquanto o critério objetivo analisará a veracidade do puffing, de forma que se o que for anunciado não corresponder à verdade, será considerada enganosa. É o caso de anúncios como "o carro mais econômico da categoria". (NUNES, 2011).

\subsection{O Teaser}

Esta técnica possui a função específica de preparar o mercado para a verdadeira campanha publicitária. Consiste na apresentação de fragmentos da campanha publicitária, visando, apenas, criar expectativa ou curiosidade no público. Não induz ao consumo de forma direta, uma vez que o produto ou o serviço só será identificado posteriormente. (GARCIA, 2010).

Na prática, o controle do CDC se dará sobre os fragmentos que compõem o todo, seja após a apresentação do fragmento final, seja sobre cada um isoladamente, como partes do todo. (BENJAMIN et al., 2012).

\subsection{Os Testemunhais}

Nunes (2011) conceitua os testemunhais como técnica de apresentação de produtos ou serviços por meio do depoimento de artistas, ou pessoas conhecidas do público consumidor, e ainda por técnicos, peritos, etc. com a finalidade de promover uma aproximação entre os consumidores e o que está sendo anunciado.

Devido à sua capacidade de conferir maior força de comunicação, persuasão e credibilidade à mensagem publicitária, o CBAP conferiu a este assunto regramento específico, em seu artigo 27.

Por essa razão, o testemunhal consiste no "depoimento, endosso ou atestado mediante o qual pessoa ou entidade diferente do anunciante exprime opinião, ou reflete observação e experiência própria a respeito de um produto". (NUNES, 2011, p. 510).

\subsection{O Merchandising}

Nunes define merchandising como a "técnica utilizada para veicular produtos e serviços de forma indireta por meio de inserções em programas e filmes”. (2011, p. 537).

Por estar em contexto não publicitário, a identificação da oferta do produto acaba prejudicada, pois o consumidor encontra-se despido de suas defesas à publicidade, de forma que toma a ficção por realidade, perdendo o senso crítico e a capacidade de escolha, o que não ocorreria num anúncio publicitário normal. (NUNES, 2011). Em resumo, Nunes declara que "O consumidor recebe a informação, mas não avalia como apelo de vendas”. (2011, p. 539).

O CDC não proíbe expressamente o merchandising, o que está vedada é a publicidade clandestina e a invisível, que é aquela que não obedece ao princípio da identificação obrigatória da publicidade. Benjamin et al. (2007) entende que essa técnica é uma forma de burlar o limite máximo de 25 minutos de publicidade por hora de programação.

Para que possa ser utilizado o merchandising, deve-se seguir a obrigatoriedade de exibição de "créditos, que correspondem à veiculação antecipada de uma informação comunicando que, naquele programa, peça ou filme, ocorrerá merchandising de específicos produtos ou serviços". (BENJAMIN et al., 2007, p. 333). Essa exibição deverá ocorrer sempre e no fim de cada fragmento, para que o consumidor que o pegou no meio também possa usufruir dessa informação.

\section{A Publicidade Ilícita}

A prática da publicidade ilícita fere o preceito constitucional do respeito à dignidade da pessoa humana, extrapolando os limites da legislação consumerista, infringindo os dois 
principais objetos protegidos pela regulação da publicidade, a vulnerabilidade do consumidor e os valores sociais. (EFING, 2012).

\subsection{Publicidade enganosa}

Esse tipo de publicidade ilícita afeta não apenas o consumidor, mas também a sociedade e o mercado como um todo, uma vez que seu objetivo principal é distorcer o processo decisório do consumidor, para levá-lo a adquirir produtos e serviços que, se estivesse mais bem informado, não o faria. (GRINOVER et al., 2007).

A publicidade enganosa é caracterizada pelo uso indiscriminado da mentira, que pode aparecer de forma deliberada, informação totalmente falsa, ou de forma discreta e dissimulada, quando presta informações apenas parcialmente inverídicas. Esse conteúdo falso deve ainda ser capaz de induzir o consumidor ao erro, ainda que de forma apenas potencial.

É necessário observar que um elemento intrínseco à atividade publicitária é o uso da arte, na licença publicitária, que deve ocorrer nos limites da realidade do produto ou serviço anunciado, não estando autorizado que a publicidade a utilize com fins escusos de forma deliberada.

Coelho (2012, p. 390) esclarece:

Pode haver, portanto, algum toque de fantasia (e de falsidade por conseguinte) nas peças publicitárias. Isso, no entanto, não representa agressão ao direito dos espectadores à mensagem verdadeira, porque a percepção do fantasioso afasta a enganosidade, descarta a possibilidade de qualquer afirmação fundada na realidade dos fatos.

O mesmo autor (2012) observa ainda que uma das finalidades do CONAR e do CBAP é a preservação do potencial econômico e lucrativo da atividade, através da racionalização do uso da fantasia, de forma a evitar que o seu uso excessivo venha a desacreditar o conjunto.

A publicidade enganosa pode ocorrer de duas formas: por comissão, onde há a mentira deliberada; ou por omissão, que ocorre quando o anunciante não informa um dado relevante para a formação da decisão do consumidor (CDC, artigo $\left.37, \S 3^{\circ}\right)$.

$\mathrm{O}$ CDC busca, por meio da repressão à publicidade enganosa, a proteção do consumidor. Dessa forma, para a sua caracterização, é dispensável a análise do elemento subjetivo, dolo e culpa do anunciante, não importando se existia a intenção de enganar, uma vez que sempre que o anúncio for capaz de induzir o consumidor a erro, restará configurada a publicidade enganosa, passível de sanção administrativa e judicial.

Os parâmetros estabelecidos pelo legislador para a mensuração do potencial de induzimento ao erro da publicidade são: I. Objetivo: corresponde ao conteúdo da mensagem e II. Subjetivo: capacidade crítica do público-alvo, consumidor atingido ou atingível.

Em relação ao conteúdo da mensagem, o CDC adota dois princípios: na proteção dos direitos individuais simples, aplica-se o princípio da transparência, que consiste na obrigação de o anunciante informar de forma prévia, ampla e adequadamente sobre o seu fornecimento, e quanto aos direitos coletivos, difusos e individuais homogêneos, adota-se o princípio da veracidade.

\subsection{Publicidade abusiva}

A publicidade abusiva é uma novidade inaugurada pelo legislador brasileiro. Ela busca tutelar valores que sejam caros à sociedade de consumo. (GRINOVER et al., 2007). O CDC, ao tratar da publicidade considerada abusiva, optou por não defini-la, mas sim, por elaborar um rol exemplificativo. (NUNES JUNIOR, 2010).

O conceito de abusividade está carregado de forte teor ético e moral. Para Nunes (2011, p. 565): “O caráter de abusividade não tem necessariamente relação direta como o produto 
ou serviço oferecido, mas sim com os efeitos da propaganda que possam causar algum mal ou constrangimento ao consumidor".

Pode acontecer de um anúncio publicitário ser ao mesmo tempo abusivo e enganoso, no entanto o direito possui mecanismos mais ágeis para detectar este, havendo, para tanto, critérios mais objetivos e precisos. Já com relação ao abusivo usa-se o critério residual, sendo abusivo tudo que contrarie o sistema de valores da $\mathrm{CF} / 88$ e das normas infraconstitucionais e que não seja enganoso. (GRINOVER et al., 2007).

Dessa forma, serão abusivas as peças publicitárias: discriminatórias, exploradoras do medo ou supertição, incitadoras de violência, dirigida aos hipossuficientes, desrespeitosas aos valores ambientais, que induzam a condutas nocivas à saúde ou segurança do consumidor, entre outras.

Conclui-se, portanto, que o critério de identificação da publicidade abusiva é o da agressão aos valores sociais, visto que a abusividade não ocorre contra um consumidor específico, mas contra toda a sociedade, o dano moral é coletivo, possuindo, portanto, caráter difuso.

\section{Considerações Finais}

O presente trabalho acadêmico buscou discutir a tutela do consumidor partindo de um debate central, consistente na relação sociedade pós-moderna, consumismo exacerbado, publicidade ilícita e os meios privados de controle dessas práticas.

A atividade publicitária não pode estar à margem do direito e principalmente da ética, uma vez que ela é dotada de um poder de longo alcance e de difícil controle, devido aos direitos que a tangenciam, tais como a liberdade de expressão. Por isso é tão salutar a criação de um órgão de autorregulamentação.

É dentro desse cenário que o CONAR surge como meio paralelo ao sistema jurídico. Sua atuação busca primordialmente a conscientização ética dos agentes publicitários, estabelecendo limites e sanções às práticas ilícitas, de forma a cumprir com o mandamento constitucional de defesa do consumidor na sua condição de vulnerabilidade e, principalmente, a manutenção da credibilidade da própria publicidade no mercado de consumo.

\section{REFERÊNCIAS}

BARROSO, Felipe. Manual de formatação de monografia jurídica. 2. ed. rev. atual. Fortaleza: FA7/Bookmaker, 2012.

BRASIL, Constituição (1988). Constituição da República Federativa do Brasil. Brasília, DF: Senado Federal, 1988.

BRASIL. Código Brasileiro de Autorregulamentação Publicitária. Disponível em: $<\underline{\text { http:// }}$ www.janela.com.br/textos/Auto-Regulamentacao.html>. Acesso em: 14/05/ 2013.

BRASIL. Código de Defesa do Consumidor. Lei 8.078, de 11 de setembro de 1990. Dispõe sobre a proteção do consumidor e dá outras providências. Brasília, DF: Poder Executivo, 1965. Disponí-

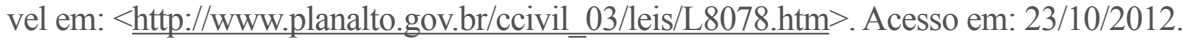

BAUDRILLARD, Jean. A sociedade de consumo. Lisboa: Edições 70, 1995.

BENJAMIN, Antônio Herman V.; MARQUES, Claudia Lima; BESSA, Leonardo Roscoe. Manual de direito do consumidor. 4. ed. Ver., atual. e ampl. São Paulo: Revista dos Tribunais, 2012.

COELHO, Fábio Ulhoa. Curso de direito comercial: direito de empresa. 16. ed. v. I. São Paulo: Saraiva, 2012. 


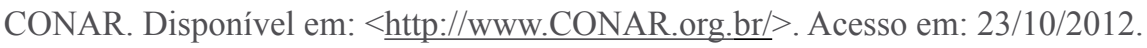

DURANDIN, Guy. As mentiras na propaganda e na publicidade. São Paulo: JSD Editora, 1997. EFING, Antônio Carlos; BERGSTEIN, Laís Gomes; GIBRAN, Fernanda Mara. "A ilicitude da publicidade invisível sob a perspectiva da ordem jurídica de proteção e defesa do consumidor". Revista de Direito do Consumidor, v. 21, no 81, p. 91-116. São Paulo: Revista dos Tribunais, jan/mar. 2012.

FADEL, Marcelo Costa. "Breves comentários ao Código de autorregulamentação publicitária do CONAR". Revista de Direito do Consumidor. v. 13, n 50, p. 153-170. São Paulo: Revista dos Tribunais, abr/jun. 2004.

GRINOVER, Ada Pellegrini et al. Código brasileiro de defesa do consumidor: comentado pelos autores do anteprojeto. 9. ed. rev., atual. e ampl. Rio de Janeiro: Forense Universitária, 2007.

JAMESON, Fredric. Pós-Modernismo: A lógica cultural do capitalismo tardio. 2. ed. São Paulo: Ática, 2007.

LOPES, Antônio Paraguassu. Ética na propaganda. São Paulo: Atlas, 2003.

NUNES, Luiz Antonio Rizzatto. Curso de direito do consumidor. 2. ed. rev., modif. e atual. São Paulo: Saraiva, 2005.

NUNES JÚNIOR, Vidal Serrano; TRETTEL, Daniela Batalha. "Limites à publicidade comercial e a proteção dos direitos fundamentais". Revista de Direito Constitucional e Internacional. v. 18, nº 70, p. 389-256. São Paulo: Revista dos Tribunais, jan/mar. 2010.

SAMPAIO, Rafael. Propaganda de A a Z. 3. ed. rev. e atual. Rio de Janeiro: Campus, 2003.

SANT'ANNA, Armando. Propaganda: teoria, técnica e prática. 7. ed. rev. e atual. São Paulo: Pioneira Thomson Learning, 2002.

XAVIER, José Tadeu Neves. "Os limites da atuação publicitária na condução de comportamentos sociais: o valor da ética no controle jurídico da publicidade". Revista de Direito do Consumidor. v. 21, nº 81, p. 118-143. São Paulo: Revista dos Tribunais, jan/mar. 2012.

\title{
CONSUMER LAW IN BRAZIL BEFORE DECEPTIVE AND ABUSIVE ADVERTISING
}

\begin{abstract}
This article has the purpose to make an analysis about the post-modern society concerning the construction of its cultural patterns and the way they are connected to the use of illicit advertising. The control over these pernicious practices and the shaping of consumers behaviour should be done in two different sectors: the legal and the private, fulfilling the constitutional commandment of consumer protection policy.
\end{abstract}

Keywords: Advertising. Consumer. Self Regulation. Deceptive and Abusive Advertising.

Data de recebimento: jun/2013 - Data de aprovação: set/2013 